\title{
Correction to: The New Security
}

\section{Correction to:}

H. Forbes-Mewett, The New Security, Crime Prevention and Security Management, https://doi.org/10.1057/978-1-137-59102-9

The original version of this book has been revised and some postpublication corrections related to copy-editing have been incorporated.

The updated online version can be found at https://doi.org/10.1057/978-1-137-59102-9 